\title{
Electrically Dewatering Microalgae
}

\author{
Robert V. Pearsall, Rhykka L. Connelly, Mark E. Fountain, \\ Clay S. Hearn, Michael D. Werst, and Robert E. Hebner \\ The University of Texas at Austin \\ Center for Electromechanics \\ 1 University Station \#R7000 \\ Austin, TX 78712, USA
}

\author{
Edward F. Kelley \\ KELTEK, LLC \\ PO Box 866 \\ Niwot, CO 80544, USA
}

\begin{abstract}
Microalgae are being developed as a source of fuels and/or chemicals. A processing challenge is dewatering the algae. Electrical approaches to dewatering include exploiting electrophoresis or electroflocculation. The reported experiments show that electrophoresis does occur but is complicated by the effects of the fluid motion. It appears that the coupling of the algal cell and the fluid can be sufficiently strong such that fluid motion effects can influence or dominate behavior. Electroflocculation appears to be a robust process. It does, however, inherently leave electrically induced trace metal flocculants in the dewatered algae.
\end{abstract}

Index Terms - Algae, dewatering, electroflocculation, electrophoresis

\section{INTRODUCTION}

MicroalgaE is an environmentally friendly, renewable energy source [1]. The term "algae" is broad and may be divided into macroalgae, commonly known as seaweed, and microalgae. Depending on their species, their sizes can range from a few micrometers to a few hundred micrometers. The species used in this study are microalgae. Cultivation of microalgae, a rapidly growing single-celled micro-organism, has also been suggested as a way to address the environmental issues of carbon dioxide $\left(\mathrm{CO}_{2}\right)$ greenhouse gas sequestration, generating renewable fuels, and wastewater remediation $[2,3$, 4]. Alternative energy research is generally viewed as important considering the continuing and increasing per-capita global energy consumption, and the reported diminishing fossil fuel reserves $[5,6]$. The current popularity of algae as a biomass energy crop may be a result of the ability of algae to grow in water of a wide range of quality including brackish waters, waste water, and salt water. In addition, algal growth concurrently sequesters carbon dioxide.

The high oil content of alga species such as Nannochloropsis sp., with a reported $29 \%$ oil, makes algae an attractive biofuel crop [7]. Microalgae cultured as a suspension, grown in optimized bioreactors has been reported at densities as high as $1 \%$ (volume/volume basis) [8], which is 10 to 100 times natural growth densities.

Because of the high water-to-algae ratio, energy efficient dewatering is a challenge in the commercialization of biofuels from algae. For algae growth to be cost-effective, the algae must be concentrated and the water returned to the growth facility. Microalgae is typically removed from large volumes of water more easily by flocculation and sedimentation than by filtration $[9,10]$, but both approaches are under active development.

An obvious approach for consideration, as algae normally carry a negative charge, is electrophoresis. In a water solution, however, both electrophoresis and electroflocculation can occur under the same set of circumstances. The research reported here was stimulated by the simple observation that if a tray of algae in its growth medium was exposed to an electric field by placing metallic electrodes on two sides of the tray and energizing them with a dc voltage, algae concentrations would occur at both electrodes (electrophoresis) and at the bottom of the tray (electroflocculation).

This research focused on assessment of the factors influencing electrophoresis and electroflocculation of algae in its growth medium. These two processes tend to be linked because, if metal electrodes are in contact with the algae and water, both processes can occur.

The microalgae selected for this work was Chlorella $s p$. Appropriate test cells were designed for these studies, including a flow-through test cell with aluminum electrodes.

\section{ELECTROPHORESIS}

Electrophoresis is the field-induced motion of a particle with respect to the fluid. Algae have a net negative charge that helps keep them separated [11]. Growth media is water based and contains required chemicals, predominantly monovalent sodium $\left(\mathrm{Na}^{+}\right)$and potassium $\left(\mathrm{K}^{+}\right)$ions, which may make up at least some of the counterions in electrophoresis. Because the algae are charged, the force resulting from an electric field could, in principle, move the algae toward an anode, thus increasing concentration.

There are obvious complexities [12] to the simple 
observation that an electric field should result in a force on the algal cell. These include:

- Microalgae experience drag forces, so it is difficult to decouple algal motion from fluid motion.

- The medium surrounding the algae cells is predominantly water with uncontrolled concentrations of neutral and ionized material, with the field acting on both the algae and the medium.

- Electrode effects include the injection of metal ions into the medium.

- Electrohydrodynamic phenomena can be induced and produce complex flow patterns depending on coupling of the charge carriers to the fluid and the influence of the test chamber on fluid motion.

From a process engineering perspective, there is another fundamental constraint that must be acknowledged. To minimize processing cost, the dewatering is ideally done in a flow process rather than a batch process. Thus, in the simplest embodiment of concentration by electrophoresis, the algae would be entrained in a fluid flow approximately orthogonal to the field. This introduces another source of flow.

To gain insight into the processes that occur, a high speed camera was used to photograph the movement of the algae as a voltage step was applied to a set of parallel electrodes. The experimental set up is shown in Figure 1. A light emitting diode (LED, Luxeon Rebel, cool white, $140 \mathrm{~lm}$ ) was used to illuminate a test cell in which algae samples were introduced by syringe injection. The LED is fan-cooled and has an aperture of about $1 \mathrm{~mm}$. The first lens, near the LED, is a 30 $\mathrm{mm}$ focal-length coated Achromat. The camera has a $512 \mathrm{x}$ 512 CMOS detector. The test cell is cylindrical with a $19 \mathrm{~mm}$ diameter and a $9.5 \mathrm{~mm}$ length along the optical axis. In the test cell, a voltage pulse with a rise time less than a nanosecond and duration of several milliseconds was applied to a suspension of the algae in its growth medium.

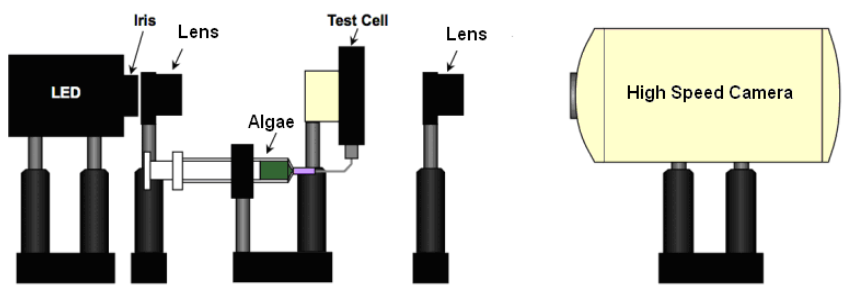

Figure 1. Schematic of the optical system from the illuminating laser to the high speed camera. The algae were introduced into the test cell using the syringe. An electric field was generated in the test cell by applying a step voltage to parallel electrodes.

The apparatus illustrated in Figure 1 produced the images shown in Figure 2.

Figure 2 shows two photographs of algae suspended in growth medium inside the test cell. Prior to the electrical pulse, the algae stream is approximately centered between the electrodes and orthogonal to the direction in which the electric field will be applied. The dark objects on either side of each picture are electrodes, with the anode on the right edge of each picture. Following the application of the voltage pulse the algae dispersion and migration toward the positive electrode can be observed. The voltage pulse has a 5 ms width and the average electric field was $1.5 \mathrm{kV} / \mathrm{cm}$. The exposure time for each of the two frames shown is $10 \mu \mathrm{s}$.

The photograph at the end of the pulse shows algal movement under conditions where effects from the electrohydrodynamic phenomena and injections from the electrodes are both minimal. In this case, the suspension of algae moves preferentially but not exclusively toward the anode, becoming significantly less dense. This effect is likely due to the fact that the media also contains positive ions that are attracted to the cathode, initiating fluid flow in that direction. Locally, the fluid flow is sufficient to overcome the force imposed by the electric field on the algal cell.

Higher electric fields were used to highlight the effects of injection from the electrodes and electrodynamic effects. This experiment was performed under the same conditions as Figure 2, with the exception of using a higher voltage (field of $3 \mathrm{kV} / \mathrm{cm}$ ). The results are seen in Figure 3. The five frames (10 $\mu$ s exposure, $200 \mu$ s between frames) illustrate the process in sequential order, during application of the electrical pulse. The first frame shows that the algae are initially attracted to both electrodes (likely due to a combination of electrophoresis and hydrodynamic drag effects as seen in Figure 2). Subsequently, emission from the cathode causes fluid motion which induces significant optical distortion $[13,14]$. As the electrical current flow continues, the anode turbulence becomes more severe. If the observation were continued, the turbulence would fill the entire inter-electrode gap mixing the suspension.

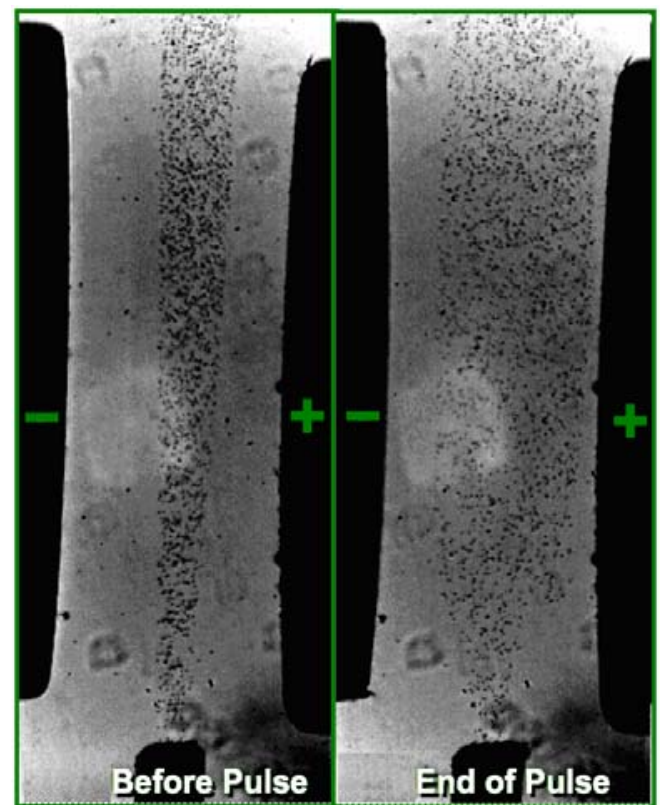

Figure 2. Microscopic images of algal movement prior to and following an applied electric field. The large dark structures in each frame are electrodes energized so that the anode is on the right as indicated. The stream of small black dots is the microalgae flowing in its medium between the electrodes. The primary effect of the pulsed electric field is to broaden the algae stream, with preferential broadening toward the anode. This is expected as the algae carry a negative charge.

This phenomenon likely results from the electrical current flow being primarily influenced by ions in the medium and/or fluid motion, and only to a lesser extent by the algal cells. If that is a correct assumption, the resistivity of the slurry is 
expected to increase with increasing algal density. This hypothesis implies that even though there is a current due to algae transport, $I_{A}$, there is also a current due to ion flow through the water surrounding the algae, $I_{i o n}$. The hypothesis is simply that $I_{i o n}>>I_{A}$. A separate experiment was performed to assess this hypothesis.

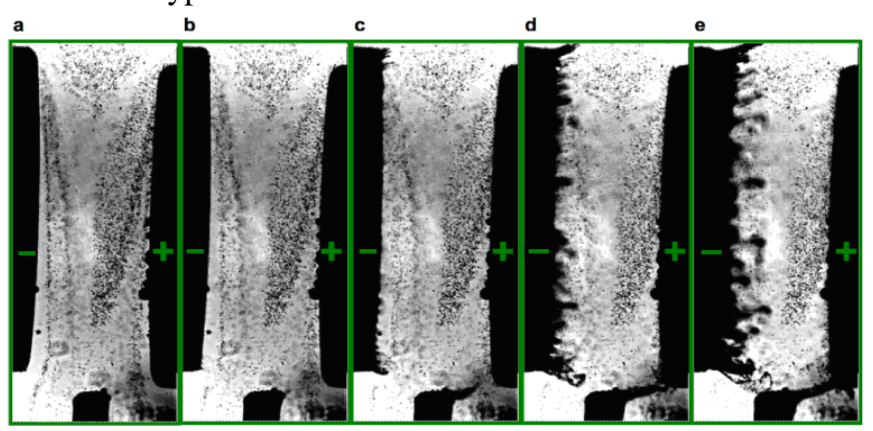

Figure 3. Time course of algal movement during an electric field pulse at higher field levels than used in Figure 1. In this case, fluid flow due to emission from the cathode is readily apparent.

In agreement with the previous observation, there is a significant decrease in conductivity with increasing algae density. The results of that test are given in Figure 4 . Particularly with lower density media, the conductivity increases as the voltage increases. Much of the increase can likely be attributed to enhanced fluid motion. The paste was placed in the test cell and allowed to dry further. This resulted in an even lower conductivity. This result is consistent with the hypothesis that the dominant conduction mechanism is via ions in the water. Additional testing would be required to ascertain whether or not there was also a contribution from changes in the algae.

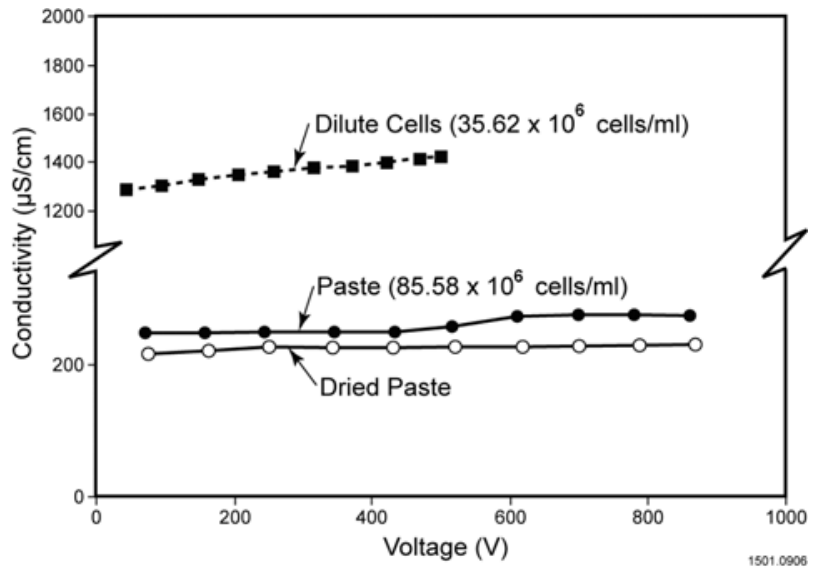

Figure 4. Conductivity of a slurry of the algae in its growth medium at different algae concentrations versus applied voltage. Cell density has a significant influence on electrical conductivity of the mixture, as expected.

An electrical test cell was constructed to validate the microscopic results on a macroscopic level. The test cell is shown in Figure 5. It consists of a machined polypropylene block with a central channel and fluid inlet and outlet holes. Aluminum electrodes lined the central channel. Provisions were made at the outlet end of the test cell for two liquid streams to exit in a volume ratio of 2:1 to evaluate additional water removal due to cell electrophoresis. A regulated dc power supply was set to the desired voltage and connected to the electrodes.
An algae-water suspension is pumped into the cell through the hole on the right side of the chamber in Figure 5. The mixture flows between the two electrodes and exits through one of two separated chambers. If the electric field moves the algae preferentially toward either electrode, a corresponding change in the concentration of algae between the two exiting streams would result.

Although some algal localization to the cathode was observed in the high-speed photomicrograph data, such a separation was not observed on the macroscopic scale. The data indicate only a slight separation under direct current (DC, $50 \mathrm{~V}$ ), consistent with the observations in Figure 2, but no significant separation in this apparatus. The fluid flow appears to dominate over electric field in the determination of algae motion.
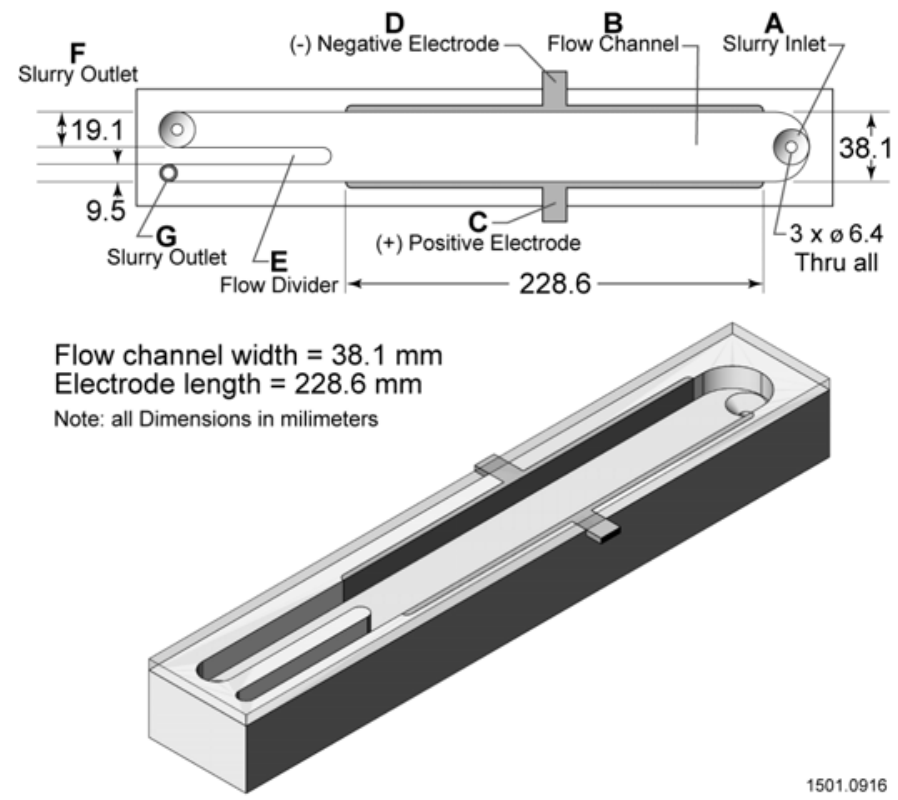

Figure 5. Electroflocculation flowthrough cell. The algae-water mixture enters through the hole on the right, $\mathrm{A}$, passes between the electrodes, $\mathrm{C}$ and $\mathrm{D}$, and exits, holes F and G, through either of the two chambers on the left.

Data were taken at various additional frequencies. The higher frequencies were not expected to yield separation as the field direction would reverse before significant displacement of algae could occur. The tests confirm the expectation.

\section{ELECTROFLOCCULATION}

Electroflocculation was reported as early as 1903 in the patent literature and has found extensive use in the petroleum industry to break emulsions and remove oils [15, 16, 17]. In traditional flocculation processes, polyvalent metal ions such as iron $\left(\mathrm{Fe}^{+3}\right)$ or aluminum $\left(\mathrm{Al}^{+3}\right)$ are added to water as salts to cause the flocculation. The algal growth media contains trace quantities of divalent calcium $\left(\mathrm{Ca}^{+2}\right)$, and magnesium $\left(\mathrm{Mg}^{+2}\right)$ ions, as well as polyvalent iron $\left(\mathrm{Fe}^{+3}\right)$ ions. Electroflocculation differs from traditional flocculation in that sacrificial polyvalent metal electrodes generate metal ions in water, replacing the external addition of a salt. Because the sacrificial electrode is consumed, an inexpensive material is recommended [15].

Microalgae do not naturally flocculate or coagulate due to, 
at least in part, their net negative charge. Algal growth medial also typically contains only trace quantities of the divalent and polyvalent cations required. The accepted mechanism by which flocculation occurs is that electrochemical reactions at the electrodes create positive, polyvalent ions [15]. These positive ions attract the negatively charged algal cells. The algal cells and polyvalent ions create a growing network of a charged neutral system. The networks can extend to other neutral systems and continue to grow into larger assemblies of flocculated algae.

Faraday's law of electrolysis says that the mass of metallic ions emitted by the anode is proportional to the change transported through the circuit. In these tests, the algae-water mixture flowed between the electrodes while a constant current was applied perpendicular to the flow. Since each element of the liquid was exposed for the same amount of time, the current is expected to be approximately proportional to the change.

\section{Test Setup}

The electroflocculation tests were conducted in the same test cell that was used for the electrophoresis testing, Figure 5. The test cell was, however, modified as indicated in Figure 6. Specifically, the two exit ports were connected together so that all of the mixture that was exposed to the electric field was collected in a single flask. The concentration of algae in the efluent was determined by an optical measurement. The optical effect was not subtle, i.e., settling was visually obvious with, but not without, exposure to the current and electric field. The optical measurement was used to provide quantitative information of the rate of settling. As the algae flocked and settled to the bottom of the vial, the algal solution became less dense. Density readings were taken periodically over a 60-minute period. Data are reported as the rate of algae clearance from the incubating solution.

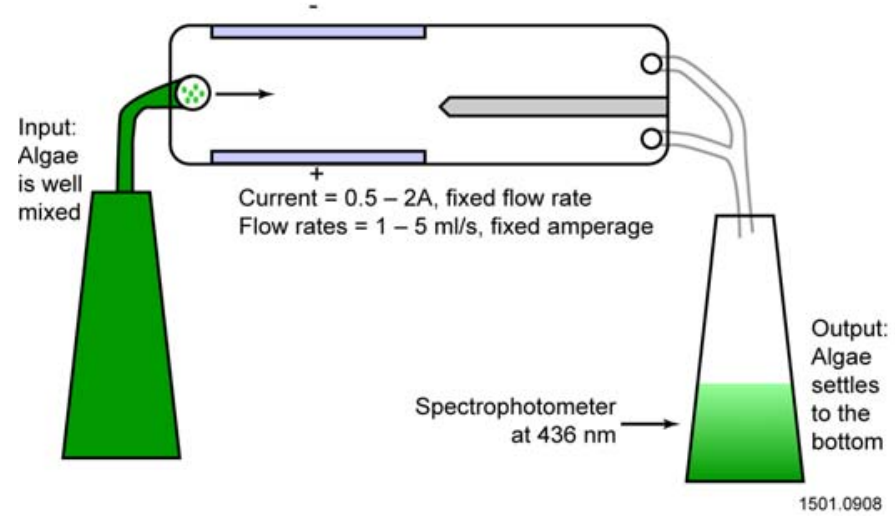

Figure 6. Apparatus used to observe electrically-induced flocculation. Unflocculated algae in water was passed through the exposure cell. A spectrophotometer was used to determine the degree of clearance by the algae. $100 \%$ clearance is interpreted as the same transmissivity as medium with no algae.

In these tests, aliquots of algae grown in indoor bioreactors were pumped at a rate of $2 \mathrm{ml} / \mathrm{s}$ between aluminum electrodes at currents of 0.5-2.0 A. The algae was pumped once through the cell. After exposure, the collected algae was held in a second flask and the flocculated algae was allowed to settle under the force of gravity. The control data was taken with zero current. The rate of algal clearance in a flask of exposed material was then measured to determine the clearance rate. The data presented are the averages of at least six samples and the error bars represent one standard deviation of the sample mean. Statistical analysis was performed by one way ANOVA. Figure 7 shows the settling of the algae as a function of time after exposure.

This analysis showed that dewatering effectiveness increased with increasing current over the range tested. Specifically, 1.0 A -2.0 A caused a significant $(p<0.01)$ increase in algae (Chlorella sp.) clearance within one minute of electroflocculation, and highly significant clearance $(\mathrm{p}<0.001$, $)$ at five minutes, compared to non-flocculated controls. At these currents, $>95 \%$ of the pure Chlorella culture was dewatered in 10 minutes.

In practical situations, however, it has typically been very expensive to maintain a monoculture. So, the process was also evaluated with a mixture of cynobacteria and Chlorella. Cyanobacteria is a common species that grows in combination with microalgae in many areas of the world.

With a mixture of cynobacteria and Chlorella, the clearance (settling) rate at a given current was slower, with less settling, and more current was required to maximize settling. Microscopic observation revealed that the cyanobacteria were fragmented following electrophoresis, and thus more likely to remain in solution.

Dewatering of the mixed cynobacteria and Chlorella cultures reached a maximum of $75 \%$ at a current of $2.0 \mathrm{~A}$. Currents of $1.0 \mathrm{~A}, 1.5 \mathrm{~A}$, and 2.0 A improved dewatering of mixed cultures significantly $(\mathrm{p}<0.05, \mathrm{p}<0.01$, and $\mathrm{p}<0.001$, respectively). By comparison, for Chlorella monocultures, 1.0 A was sufficient to clear algae; $80 \%$ and $100 \%$ within five and 20 minutes, respectively. While this process appeared to separate the Chlorella from the cyanobacteria, no quantitative measurements were performed to determine separation efficiency.
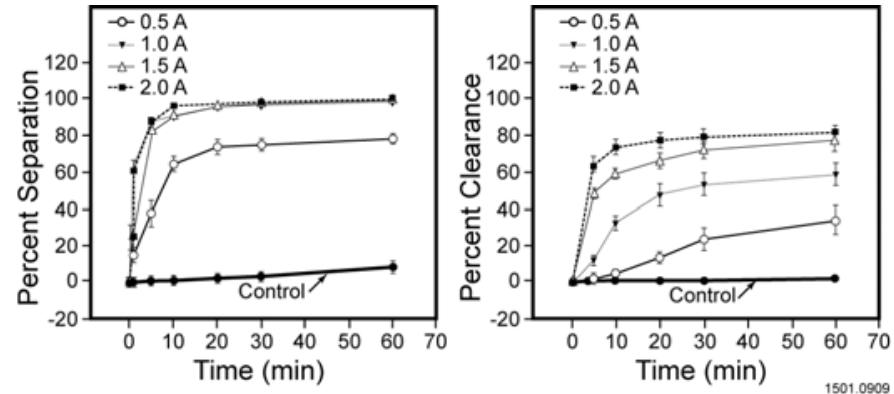

Figure 7. Rate of algal clearance following electroflocculation at various currents (Left: Chlorella monoculture, Right: Chlorella and Athrospira mixed culture.

For the algae mixture, increasing the current also demonstrated increasing dewatering effectiveness. Under these test conditions, $1.5 \mathrm{~A}$ and $2.0 \mathrm{~A}$ were most efficient, effectively dewatering the algae (by $67 \%$ and $77 \%$ respectively at $2 \mathrm{~h}$ ). Most of the dewatering occurred within the first five minutes. Lower currents were less effective (0.5 A and 1.0 A gave $22 \%$ and $50 \%$ algae clearance, respectively at $2 \mathrm{~h}$ ); additional time did not significantly improve dewatering at lower applied current.

To determine flow rate effects, similar data were taken at a current of $1 \mathrm{~A}$ at flow rates of $1-5 \mathrm{ml} /$ minute. Experiments 
were performed, with algae at densities of $0.2 \mathrm{~g} / \mathrm{L}$ and $0.6 \mathrm{~g} / \mathrm{L}$. The algal density was measured by two methods: 1) dry weight of the biomass, and 2) cell counts based on measurements using a hemocytometer. Hemocytometer calculations were based on counts of 10 random fields. Figure 8 illustrates density making an observable difference.

This difference is presumably due to the fact that the flocked algal cells have a greater likelihood of continuing to flocculate into larger ionic networks at the higher density. It is also interesting to note that the algae were $50 \%$ dewatered by one minute at $5 \mathrm{ml} / \mathrm{s}$ for lower density $(0.2 \mathrm{~g} / \mathrm{L})$ Chlorella $s p$. cultures, but that the higher density culture was slower to clear.
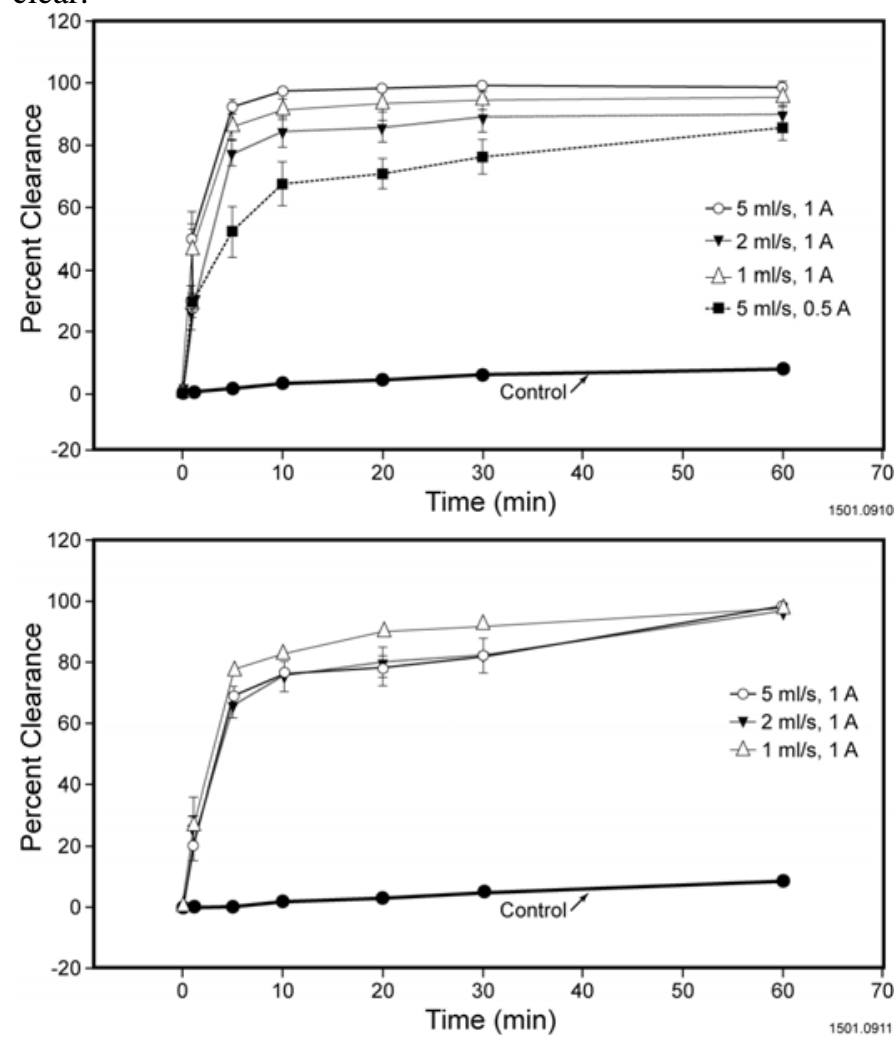

Figure 8. Settling vs. time for different flow rates and a current of $1.0 \mathrm{~A}$. The upper chart shows results with an algal density of $0.2 \mathrm{gm} / \mathrm{l}$ and the lower a density of $0.6 \mathrm{gm} / \mathrm{L}$.

\section{CONCLUSIONS}

Algae in its growth medium constitutes a complex fluid. Little is known about the electromechanical properties of the fluid. While both electrophoresis and electroflocculation occur, these are not likely to be simple independent phenomena in commercial systems. Even microalgae are sufficiently large that electrohydrodynamics can dominate over simple electrostatic considerations. Thus, the application of an electric field does not yield a simple unidirectional flow of negatively charged algae to the anode. Because of the complex response, it is quite challenging to design an effective dewatering approach based solely on electrophoresis.

In addition to electrophoresis, electroflocculation occurs when the electrodes are in contact with the fluid. While electroflocculation appears to be effective as a dewatering approach, by its nature, it leaves residual medals in the concentrated algae. Since this trace metal can reduce the value of the products produced, dewatering methods that do not leave trace metals would generally be preferred.

Thus, both processes occur in systems containing microalgae in their growth medium. Both appear to require further development if they are ever to be viable candidates for cost effective dewatering of microalgae at a commercial scale.

\section{ACKNOWLEDGMENT}

M.E.F. thanks Dr. Jerry Brand and Dr. Martin Poenie of the University of Texas, and Adelheid Kuehnle of Kuehnle AgroSystems for critical discussion regarding algal growth and handling. This work was supported in part by OpenAlgae.

\section{APPENDIX}

Organism and growth conditions. The microalgae Chlorella sp., (Strain KAS01110803) were obtained from Kuehnle AgroSystems, Inc., (Honolulu, Hawaii, USA). The algae suspension cultures were grown in six-liter Erlenmeyer flasks with continuous aeration at an airflow rate of $250 \mathrm{ml} \mathrm{min}^{-1}$. The flasks were arranged on a rack illuminated with daylight fluorescent lamps at a light intensity of $120 \mu \mathrm{mol}$ photons $\mathrm{m}^{-2}$ $\mathrm{s}^{-1}$. The cultures were maintained with a circadian light: dark cycle of $12: 12 \mathrm{~h}$ at $25^{\circ} \mathrm{C}$. The microalgae Chlorella $s p$. were grown as non-axenic cultures on F2 media [18], modified by replacing the sodium nitrate (nitrogen source) with urea (equimolar on a nitrogen basis).

Chlorophyll a (Chl a) Spectrophotometric Measurement. The Chl $a$ spectrophotometric measurements were performed at the chlorophyll Soret band $(430 \mathrm{~nm})$, using a Bausch \& Lomb Spec20 spectrophotometer (10 nm bandwidth) [19]. Measuring the Chl $a$ absorbance at $430 \mathrm{~nm}$ in the Soret band, as compared to the Q-band $(630-700 \mathrm{~nm})$, results in a calculated 3.4-fold sensitivity improvement and is also thought to eliminate the interference from accessory pigments, observed at wavelengths above $460 \mathrm{~nm}$, specifically in the Qband [20].

\section{REFERENCES}

[1] E. Waltz, "Biotech's green gold?" Nature Biotechnology, Vol. 27, No. 1, pp. 15-18, 2009.

[2] B. Wang, Y. Li, N. Wu, and Christopher Q. Lan, "CO(2) bio-mitigation using microalgae,” Applied Microbiology and Biotechnology, Vol. 79, No. 5, pp. 707-718, January 2008.

[3] A. B. M. S. Hossain, A. Salleh, A. N. Boyce, P. Chowdhury, and M. Naqiuddin, "Biodiesel fuel production from algae as renewable energy," American Journal of Biochemistry and Biotechnology, Vol. 4, No. 3, pp. 250-254, 2008.

[4] W. Mulbry, S. Kondrad, C. Pizarro, and E. Kebede-Westhead, "Treatment of dairy manure effluent using freshwater algae: Algal productivity and recovery of manure nutrients using pilot-scale algal turf scrubbers,” Bioresource Technology, Vol. 99, pp. 8137-8142, 2008.

[5] M. R. Raupach, G. Marland, P. Ciais, C. LeQuere, J. G. Canadell, G. Klepper, and C. B. Field, "Global and regional drivers of accelerating CO2 emissions,” PNAS, Vol. 104, No. 24, pp. 10288-10293, June 12, 2007.

[6] E. I. Administration, International Energy Outlook 2009, U.S. D. o. Energy, Ed. U.S. Department of Energy, Washington, D.C., 2009.

[7] L. Gouveia and C. Oliveira Ana, "Microalgae as a raw material for biofuels production," Journal of Industrial Microbiology and Biotechnology, Vol. 36, No. 2, pp. 269-274(6), February 2009. 
[8] R. K. Mandalam and B. O. Palsson, "Elemental balancing of biomass and medium composition enhances growth capacity in high-density Chlorella vulgaris cultures,” Biotechnology and Bioengineering, Vol. 59, No. 5, pp. 605-611, September 1998.

[9] R. Divakaran and V. N. S. Pillai, "Flocculation of algae using chitosan," Journal of Applied Phycology, Vol. 14, No. 5, pp. 419-422(4), October 2002.

[10] C. M. Palmer, Algae and water pollution : an illustrated manual on the identification, significance, and control of algae in water supplies and in polluted water, Municipal Environmental Research Laboratory, O. o. R. a. D., U.S. Environmental Protection Agency, Washington, Ed. U.S. Govt. Print. Off.: Cincinnati; pp 57-59, 1978.

[11] E. Molina Grima, E. Belarbi, F. G. Acién Fernández, A. Robles Medina, and Y. Chisti, "Recovery of microalgal biomass and metabolites: process options and economics,” Biotechnology Advances, Vol. 20, No. 7-8, pp. 491-515, January 2003.

[12] M. Hilaire, C. Marteau, and R. Tobazeon, "Apparatus developed for measurement of resistivity of highly insulating liquids," IEEE Transactions on Electrical Insulation, Vol. 23, No. 4, pp. 779-787, August 1988

[13] H. T. Wang and J. D. Cross, "The interpretation of electrohydrodynamic mobility under unipolar injection in dielectric liquids," Proc. $3^{\text {rd }}$ Intl. Conf. Properties and Applications of Dielectric Materials, Tokyo, Japan, pp. 264-266, July 1991.

[14] M. Haidara and P. Atten, "Role of EHD motion in the electrical conduction of liquids in a plane-blade geometry,” IEEE Trans. Industry Applications, Vol. IA-21, pp. 709-714, May/June 1985.

[13] J. P. K. Koren and U. Syversen, "State-of-the-art electroflocculation," Filtration \& Separation, Vol. 32, No. 2, pp. 153-156, February 1995.

[14] I.F. Saur, S. Rubachs, J.S. Forde, G. Kjaerheim, and U. Syversen, "Electroflocculation: Removal of oil, heavy metals and organic compounds from oil-in-water emulsions," Filtration \& Separation, Vol 33, No. 4, pp. 295-303, 1996.

[15] S. Rubach and I. F. Saur, "Onshore testing of produced water by electroflocculation,” Filtration \& Separation, Vol. 34, No. 8, pp. 877882, October 1997.

[16] CCMP The Provasoli-Gulliard National Center for Culture of Marine Phytoplankton. https://ccmp.bigelow.org/home.

[17] G. R. Seely and R. G. Jensen, "Effect of solvent on the spectrum of chlorophyll," Spectrochimica Acta, Vol. 21, pp. 1835-1845, 1965.

[18] C. C. Trees, D. K. Clark, R. R. Bidigare, M. E. Ondrusek, and J. L. Mueller, "Accessory pigments versus chlorophyll a concentrations within the euphotic zone: a ubiquitous relationship," Limnology and Oceanography, Vol. 45, No. 5, pp. 1130-1143, 2000.

\section{BIOGRAPHIES}

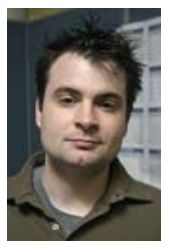

Robert V. Pearsall received his B.S. in Mechanical Engineering in 2004 from the University of Texas at Austin and is now a Research Engineer there at the Center for Electromechanics. He has extensive experience in prototype design and manufacturing and has contributed to a variety of research projects during, participating in concept generation, prototype development, design, analysis, testing, project planning, internal documentation, and external publications. Since May 2008, Mr. Pearsall has been a key team member in the Algae Oil Extraction Program centered on advanced biofuels and renewable energy. He became the Secondary Lead Mechanical Engineer and currently serves as a Project Team Leader for the program.

Rhykka L. Connelly received her B.S. and Ph.D. in Cell Biology in 2000 and 2006, respectively, from Northern Illionois University in DeKalb, Illinois. She joined the University of Texas in Austin (UT) Center for Electromechanics in February 2009. UT is conducting a multidisciplinary research and development program directed toward cost-effective extraction of renewable algal oil and other industrially relevant biomolecules. Dr. Connelly has directed the activities in the biochemical processing laboratory, including detailed analysis of UT and customer algae, training of technical staff, and development of projects and intellectual properties pertaining to the algae program.

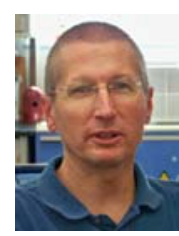

Mark E. Fountain, Ph.D., graduated from SUNY Plattsburgh in 1980 with a degree in Chemistry. He received his MS in Inorganic Chemistry in 1986 from the University of Delaware. He worked in the bulk pharmaceutical industry at Johnson Matthey Biomedical Materials in New Jersey and Epix Medical in Cambridge, Massachusetts for 15 years. Returning to school, he received his Ph.D. in Organic Chemistry from the University of Texas at Austin in 2008. He worked in a post-doctoral position in the Chemistry Department Mass Spectrometry facility prior to accepting an Algae Process Engineering post-doctoral position at the Center for Electromechanics at the University of Texas at Austin.

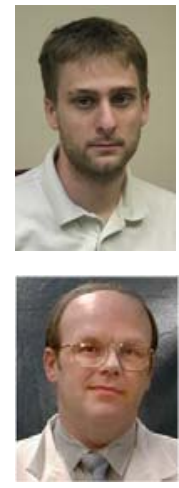

Clay S. Hearn obtained his BS and MS in Mechanical Engineering from the University of Texas at Austin in 2001 and 2008, respectively. He has been a Research Engineer at the Center for Electromechanics at the University of Texas at Austin since 2002 and is currently pursuing his Ph.D. in Mechanical Engineering at the University of Texas in Austin.

Edward F. Kelley, Ph.D., graduated from the University of Idaho in 1970 with a degree in Physics. He received his Ph.D. in Experimental Atomic Physics from Montana State University in 1977. He started in a post-doctoral position at NIST in high-voltage impulse measurements using the electro-optical Kerr effect. He continued at NIST as a staff member for approximately 11 years, investigating liquid dielectric breakdown and high-voltage pulse-measurement techniques. In 1988, he received the R\&D 100 award for an Image Preserving Optical Delay designed for photographing random events before they happen but after they occur. After going to Idaho to get a taste of private consultation and university teaching, he returned to NIST in 1992 to work in the Flat Panel Display Laboratory of the Display Metrology Project to assist industry in developing measurement standards to quantify display quality. He has served as chair and main author of the Display Metrology Committee of VESA that produced the Flat Panel Measurements Standard (FPDM) and continues as editor and main author of its extension, the Display Measurements Standard, under the International Committee for Display Metrology of the Society for Information Display.

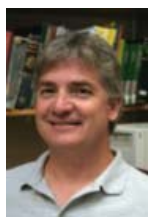

Michael D. Werst is Senior Engineering Scientist at the Center for Electromechanics at the University of Texas at Austin. He has over 27 years of experience working in research and development, including: principle investigator for high power and energy prototype and thermal analysis, and materials and process engineering. He has more than 70 technical publications.

Mr. Werst currently is the Program Manager for the Algae Oil Extraction Program and is responsible for the scale up of the electromagnetic lysing process and end-to-end oil processing commercialization efforts. Previously, he was the Program Manager for CEM's roll of developing the power supply for the US Navy's Electromagnetic Aircraft Launch System. Other recent programs include development of high density motors and generators using HTS trapped field magnets and development of magnetic gearboxes for wind turbine applications.

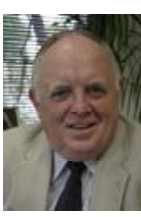

Robert E. Hebner, Ph.D., (S'70-M'71-SM'83-F'93) is Director of the Center for Electromechanics at the University of Texas at Austin. The Center develops technology, primarily novel motors, generators, and suspension components, and teams with companies to get the technology into the market.

Previously, Dr. Hebner was the acting Director of the U.S. National Institute of Standards and Technology (NIST). In addition, he has directed NIST's Electronic and Electrical Engineering Laboratory, a laboratory with a staff of more than 250. He also worked at the Defense Advanced Research Projects Agency where he developed programs to improve semiconductor manufacturing.

Throughout his career, Dr. Hebner has been active in having authored or coauthored more than one hundred technical papers and reports. He has extensive experience in international technology programs. This work included the modernization of the measurement systems needed to support global trade and the assessment of the effectiveness of government technology programs in stimulating domestic economies. 